\title{
Unbundling Business Processes to Fine-Grained E- Services through the Next Generation EIS Frameworks ${ }^{1}$
}

\author{
Seyyed Mohsen Hashemi ${ }^{1}$, Mohamad Teshnehlab ${ }^{2}$ and Mohamadreza Razzazi ${ }^{3}$ \\ ${ }^{1}$ Computer Engineering Department, Science and Research Branch, Islamic Azad \\ University, Chairman of Iran Society for EIS Research, Iran Hashemi@sr.iau.ac.ir \\ ${ }^{2}$ Computer Engineering Department, AmirKabir University of Technology, Iran \\ ${ }^{3}$ Electronic Engineering Department, KNT University, Tehran, Iran
}

\begin{abstract}
Nowadays, Enterprise Information Systems are based on TPS, MIS, and DSS and organizations are maturing to make the baselines of their Business, Enterprise, and Technology architectures based on the Service Oriented Strategies and Architectures (SOSA). The traditional EIS frameworks make their Business, Enterprise, and Technology baselines on the Business Processes or Business Usecases and they must be unbundled through the Electronic Services to realize the SOSA.

The Next Generation EIS Frameworks offer a full range of E-Service enterprise patterns that include the development of comprehensive strategies to integrate internet based solutions, E-Business, E-Commerce, and E-Government disciplines, E-Service technologies, and methodologies into the software sensitive organizations. In addition to, the Next Generation EIS Frameworks focus to facilitate the working of Service Requesters, Service Brokers, and Service Providers, in both Provider-Centric SOA and Consumer-Centric SOA perspectives over a Grid. Next Generation EIS Frameworks are Enterprise Information Systems to manage their Integrated Services \{E(IS)2\}.This paper would explain what the Next Generation EIS Frameworks are and instantiates ISRUP E-Service Framework as an instance of the Next Generation EIS Frameworks. The theme of this paper is to specify the role of E-Services to promote commercial and governmental unbundling affairs by way of using the Next Generation EIS Frameworks which developed to leverage E-Governments, E-Businesses, and E-Commerce though just the added-value E-Services. In addition to, This paper shows the main features of the Next Generation EIS Frameworks which they are Grid-Centric, X2Y-Centric, E-Service Centric, Collaborative-Centric base on new Enterprise Architecture Frameworks, and they are Data and Service-Integration Oriented.
\end{abstract}

Keywords: SOA, SOSA, EIS Framework, E-Service, ISRUP E-Service Framework, E(IS)2, Data and Service-Integration, Grid, Next Generation EIS Frameworks

'An extended version of this paper has been planed to present in a special session entitled "Next Generation EIS Frameworks!" in CONFENIS 2007

Please use the following format when citing this chapter:

Hashemi, S. M., Teshnehlab, M., Mohamadreza, R., 2007, in IFIP International Federation for Information Processing, Volume 255, Research and Practical Issues of Enterprise Information Systems II Volume 2, eds. L. Xu, Tjoa A., Chaudhry S. (Boston: Springer), pp. 983-991. 


\section{INTRODUCTION}

Since the computers have been created, three concepts have being developed more: Infrastructures, Data, and Functions.

In the first era of the centralization (Mainframe era); the nations were specified by the Countries, the relations between businesses were at the Participation level, trading was mutually between the businesses on behalf of the governments, distributions of the information were restricted to the countries' borders, knowledge was locally, and focus in the cyberspace was on the Infrastructure.

In the second era of the centralization (Web era); the nations are specified by the Unions, the relations between businesses are at the Partnership level, trading is partially mutual and partially through the exchanges and marketplaces between the businesses with supervision of the third parties, distributions of the information are being controlled to the union's borders, knowledge is partially local an partially global, and focus in the cyberspace is on the Data.

In the third era of the centralization (Grid era); the nations will be as the Global Village, the relations between businesses will be at the Collaboration level, trading will be in the public cybermarkets for the businesses on administration of the UNOs, the information will be distributed in the globe, knowledge will be globally, and focus in the cyberspace will be on the Function.

The Grid era needs an EIS framework to realize the third era of the centralization and we believe in that the SOA on behalf of SOSA is being matured as a strategy to represent the Functions by way of realizing and adopting the future and new changing requirements in the format of added-value E-Services [1,2].

Chapter 2 focuses on "Grid Based EIS Frameworks". What comes after in chapter 3 is "The Features of the Next Generation EIS Frameworks". "The role of the EServices in the Next Generation EIS Frameworks" is elaborated in chapter 4. Finally, in chapters 5, "ISRUP E-Service Framework as instance of the Next Generation EIS Frameworks" is instantiated and depicted in detail.

\section{GRID BASED EIS FRAMEWORKS}

The future technology to have a tightly coupled network to support the globalization is the Grid. In a simple manner, a grid has involved some independent network-node in a mesh structure. In the Next Generation EIS Frameworks, the geographical situation of a grid node can be International, National or State. In addition to, each grid node could be as a service provider, service requester or service broker or a combination of them as table 1 [3].

Table1. Nine Situation of Each Grid Node

\begin{tabular}{|c|c|c|c|}
\hline Grid Node & Service Provider & Service Requester & Service Broker \\
\hline International & ISP & ISR & ISB \\
\hline National & NSP & NSR & NSB \\
\hline State & SSP & SSR & SSB \\
\hline
\end{tabular}




\section{THE FEATURES OF THE NEXT GENERATION EIS FRAMEWORKS}

The Next Generation EIS Frameworks offer a full range of E-Service enterprise patterns that include the development of comprehensive strategies to integrate internet based solutions, E-Business, E-Commerce, and E-Government disciplines, E-Service technologies, and methodologies into the software sensitive organizations. In addition to, the Next Generation EIS Frameworks focus to facilitate the working of Service Requesters, Service Brokers, and Service Providers, in both Provider-Centric SOA and Consumer-Centric SOA perspectives over a Grid. The Next Generation EIS Frameworks are Enterprise Information Systems to manage their Integrated Services $\{\mathrm{E}(\mathrm{IS}) 2\}$ as figure 1. The Next Generation EIS Frameworks are Collaborative-Centric base on the new Enterprise Architecture Frameworks which they are Data and Service-Integration Oriented as depicted in figure 2.

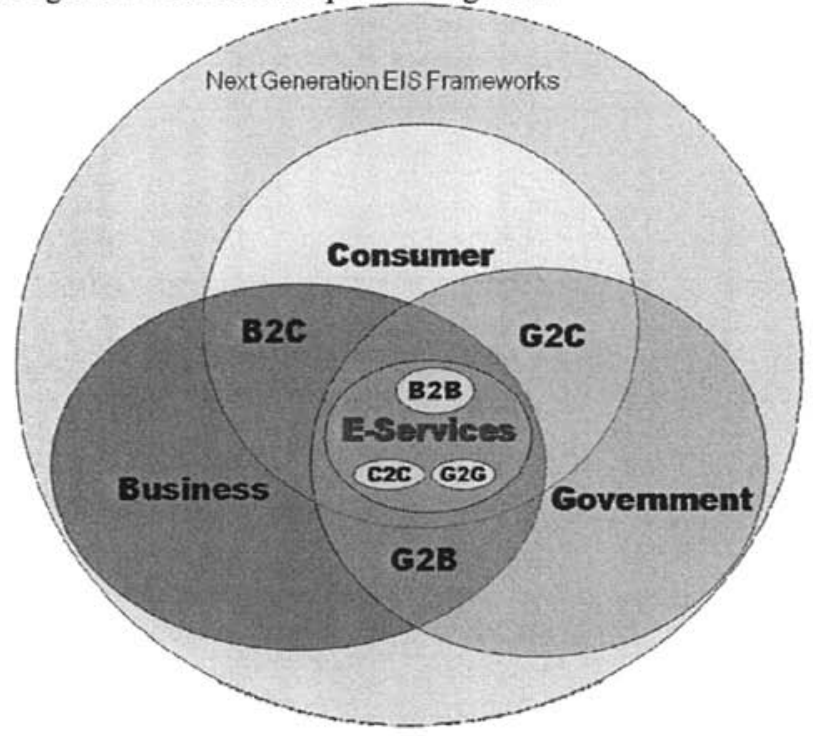

Figure 1. The Next Generation EIS Frameworks are E-Service Centric 


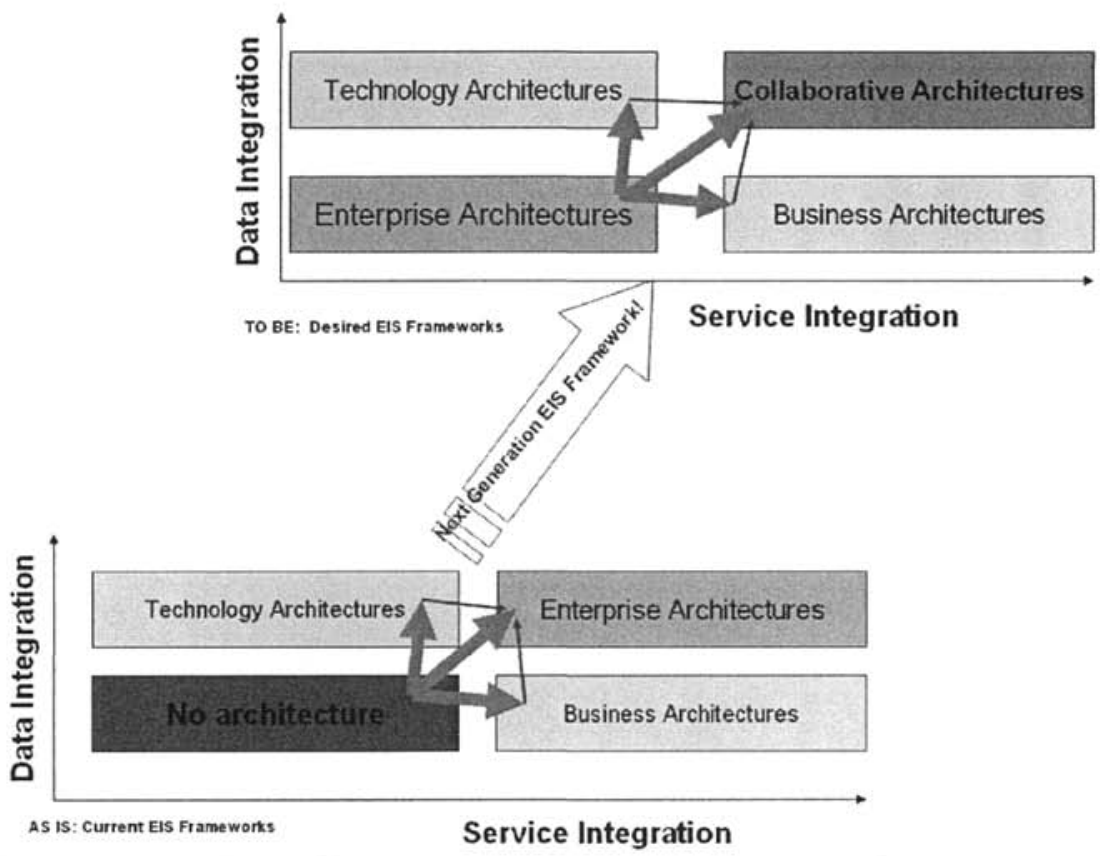

Next Generation EIS Framework! Iran Society for EIS research, IFIP, Beijing 2007

Figure 2. The Next Generation EIS Frameworks are Collaborative-Centric Based on the New Data and Service-Integration Oriented Enterprise Architecture Frameworks

\section{THE ROLE OF THE E-SERVICES IN THE NEXT GENERATION EIS FRAMEWORKS}

The 3 Architectural Abstraction Layers of the Next Generation EIS Frameworks as figure 3 are Infrastructure for E-Services, E-Services Provisioning, and Using Eservices.

The structure of the layers "Infrastructure for E-Services" and "E-Services Provisioning" is classified in figure 4. In this UML class diagram, syntax and semantic of the relationships for Added-Value Services, Services, Service Resources, and Service Collaboration are modeled. In addition to, a Service could be Simple or Composite, and each Service has a Grid Node ID to represent its association with the Grid nodes. 


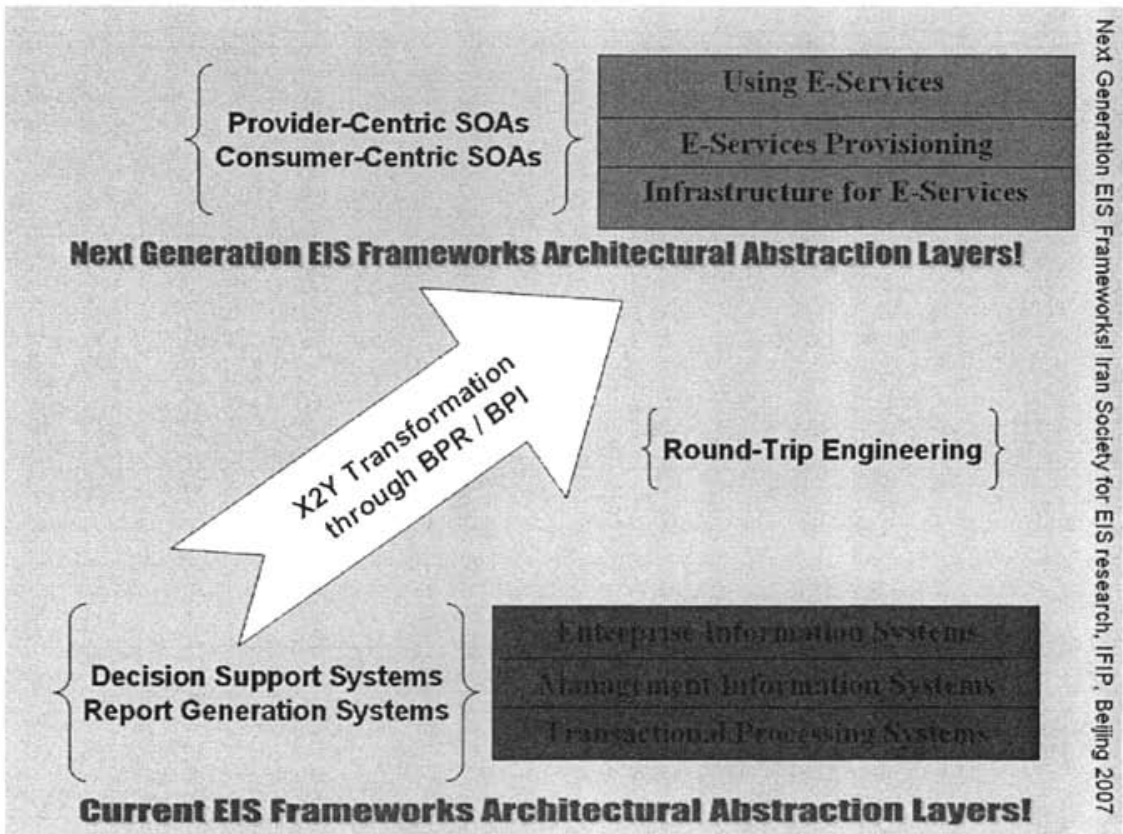

Figure 3. The Architectural Abstraction Layers of the Next Generation EIS Frameworks

In addition to, the structure of Service Actors, Services, and Service Actions is specified in a UML Class diagram as figure 5. There are two business Packages entitled as Service Actors and Services. A Service Actor is an instance of a Service Requestor, Service Broker, and/or Service Provider. A Business, a Resident (Consumer or Citizen), and a Government party could be as instance of a Services Actors Class. The structure of a Service is elaborated in detail in figure 4. moreover, an Action in association of (a Service Actor, a Service) could be as an effecter to Registry ID, Grid Node ID, and IsComposite attributes and could be triggered on Find(), Bind(), Publish(), Subscribe(), and Notify() methods [1, 2].

\section{ISRUP E-SERVICE FRAMEWORK AS INSTANCE OF THE NEXT GENERATION EIS FRAMEWORKS}

The Rational Unified Process is a software engineering process developed and marketed originally by Rational Software, and now IBM. It is a disciplined approach to assigning and managing tasks and responsibilities in a development organization. The goal of this process is to produce, within a predictable schedule and budget, highquality software that meets the needs of its end users [4]. 


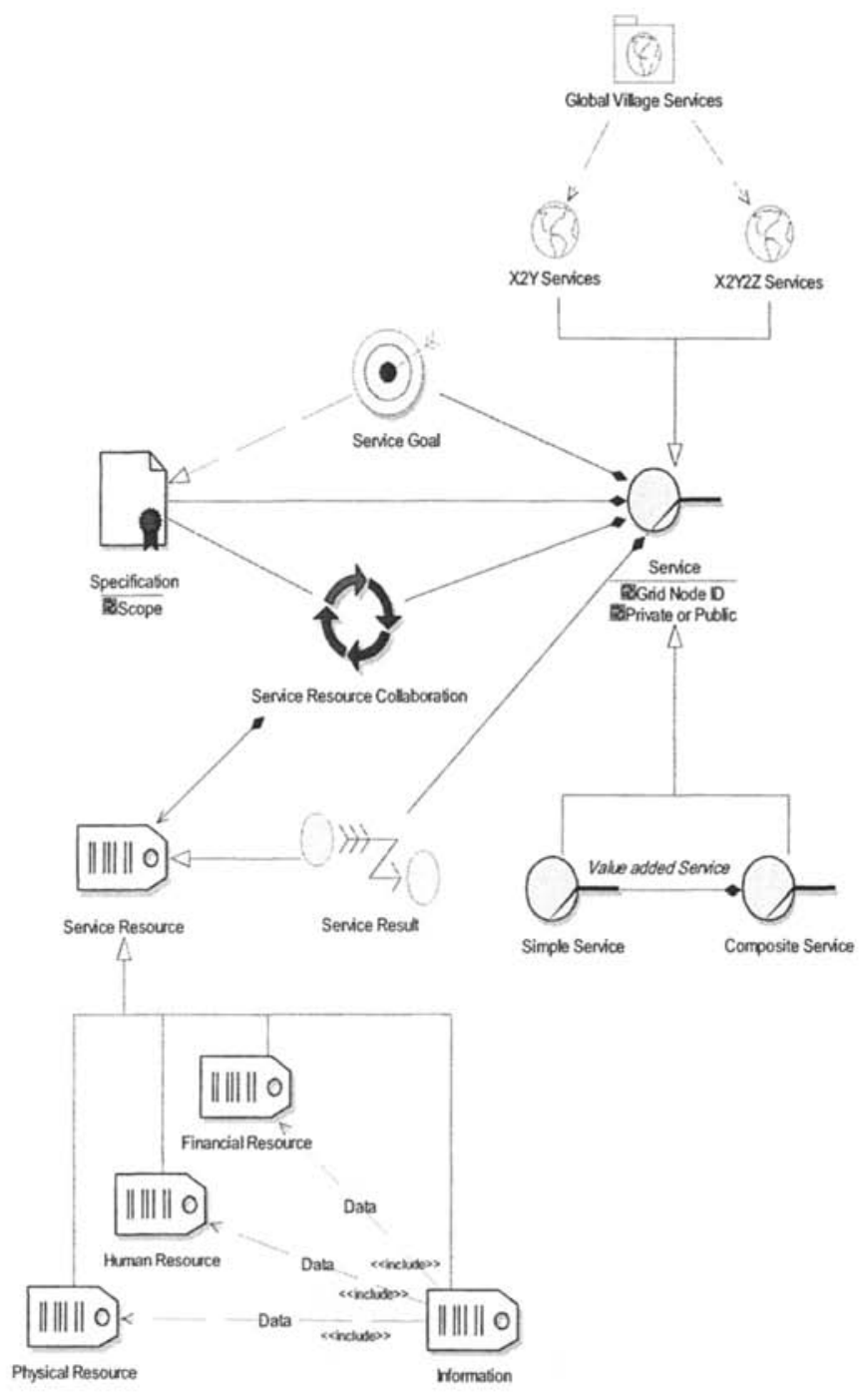

Figure 4. UML Class Diagram: Syntax and Semantic of the Relationships for AddedValue Services 

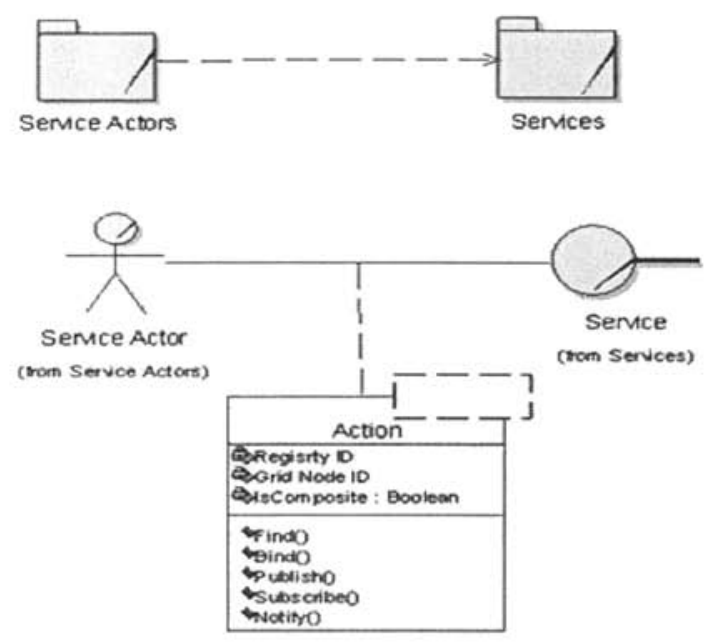

Figure 5. UML Association Class Diagram: the Structure of Service Actors, Services, and Service Actions

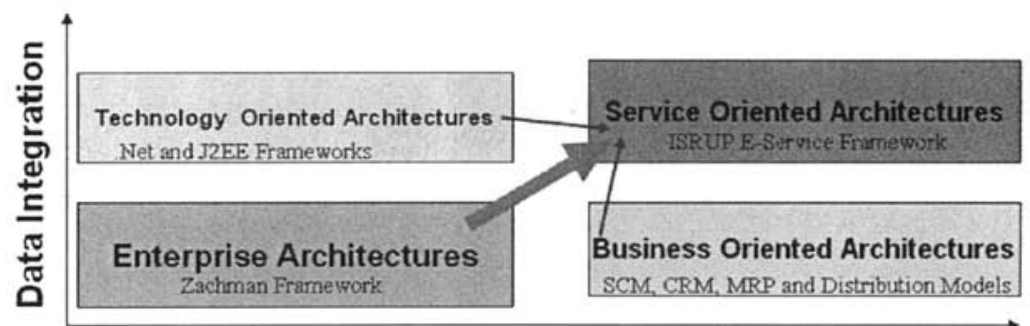

Next Generation EIS Frameworks

\section{Service Integration}

\section{Figure 6. ISRUP E-Service Framework as Instance of the Next Generation EIS} Frameworks

ISRUP is an E-Service framework for Agile Enterprise Architecting through Unified Modeling Language (UML) and RUP terminology to improve the enterprise architecture of business enterprises moreover, ISRUP E-Service Framework has 40 enterprise patterns to apply an iterative process for continuous improvement by way of information system architecting. ISRUP E-Service framework depicted that the convergence of E-Business, E-Commerce and E-Government through just E-Services $[5,6]$.

Each enterprise that wants to be as a service requester, service provider and service broker, should apply ISRUP enterprise patterns to be prosperous. ISRUP stands on 
Integrated Services-Information Systems based on Rational Unified Process terminology. ISRUP E-Service framework is used by some parts of government and businesses to make informative and reusable documents as their assets. For more information please see www.isrup.info [6-8].

ISRUP E-Service framework is derived from Zachman enterprise architecture framework and IBM Rational software development process. The framework mainly uses RUP and UML terminologies respecting to the enterprise architecture documentation. The framework doesn't claim to use the same terms and expressions as Zachman framework and RUP process, but according to the facts in the enterprises (especially Government and Businesses); it has tried to develop framework components with respect to the future technologies (SOA) and the past useful experiences. ISRUP E-Service Framework consists of 5 views (Stakeholder, Analyst, Architect, Designer and Developer) and 8 models (Proof, Process, Place, People, Period, Purpose, Practice, and Project (8P)) [6-9]. Additionally, ISRUP E-Service Framework has two dimensions; "5 Views" and "8P Models" which they are explored in brief as the follow.

" 5 Views", The 40 enterprise patterns fit into 5 views that don't necessarily adapt with the views of other frameworks syntactically, semantically and pragmatically. These views are described as follows $[6,8,9]$.

"8P Models", Proof, Process, Place, People, Period and Purpose models are considered extensions of what, how, where, who, when and why in the Zachman framework, consecutively. Practice and Project models are added to the Zachman to support and leverage the experiences and resolving the problems and changes in terms of projects.

\begin{tabular}{|c|c|c|c|c|c|c|c|c|}
\hline Vien. & Proof: & Process & eloce & Peopis & Period & Purpose & Prestice & Broject \\
\hline Spakcholder & & & & & 0 & ROI & & $\sum_{-\infty}^{n}$ \\
\hline propest & & & & 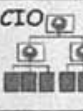 & 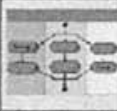 & & $\mathbf{U}$ & \\
\hline Nrohitest: & & & & & $\begin{array}{l}5=4 \\
1=3\end{array}$ & & 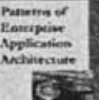 & RFPs \\
\hline Desiger & & 它 & & & हn & & 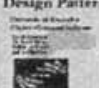 & वृत्] \\
\hline oserbper. & & & & a & 무 & 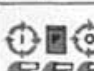 & Refecturing & \\
\hline
\end{tabular}

Figure 7. Dimensions of ISRUP E-Service Framework 
Unbundling Business Processes to Fine-Grained E-Services through the Next Generation EIS

\section{REFERENCES}

1. S.M. Hashemi, Streamlining the Global Village Grid through Unifying E-Services, Technical Review, Iran Society for EIS Research (2007-05-E03).

2. S.M. Hashemi, Streamlining the Global Village Grid through Unifying E-Governments, E-Businesses and E-Commerce. Ph.D thesis, Science \& Research Branch, Islamic Azad University, Tehran (2007).

3. S.M. Hashemi, Leveraging E-Government and E-Business Services through ISRUP EService Framework, Services Sciences, Management and Engineering, Education for the 21st Century (The IBM Palisades conference center: New York, 2006).

4. P. Kruchten, Rational Unified Process - An Introduction, 3rd edition (Addison-Wesley, 2003).

5. S.M. Hashemi, M. Razzazi, and M. Teshnehlab, Service Oriented Privacy Modeling in Enterprises with ISRUP E-Service Framework, W3C Workshop on Languages for Privacy Policy Negotiation and Semantics-Driven Enforcement, JRC, European Commission (Italy, 2006).

6. S.M. Hashemi, M. Razzazi, and A. Bahrami, ISRUP E-Service Framework for agile Enterprise Architecting, in Proc. of Third International Conference on ITNG, Las Vegas, USA, 0-7695-2497-4/06 (C) 2006 IEEE (2006).

7. S.M. Hashemi, M. Razzazi, and M. Teshnehlab, ISRUP E-Service Framework Balanced Scorecard to measure the capabilities from the methodologies, processes, notations, life cycles, and standards, in Proc. of The IFIP International Conference on Research and Practical Issues of Enterprise Information Systems (Vienna, Austria, 2006)

8. S.M. Hashemi, Business Process Improvement through ISRUP, Requirement Driven Approach with UML (ISBN: 964-7073-56-9)(2004).

9. S.M. Hashemi, Enhancement of a Software Development Process Pattern for Traceability of Artifacts in the RUP Framework, M.S. thesis, Tehran Polytechnic University /Amirkabir University of Technology (2003). 